\title{
Synthesis, Experimental and Theoretical Characterization of Co (III) Complexes of 2-Hydroxinaphthaldehyde
}

\author{
Rahman Alizadeh*, Nader Ghazinia
}

\begin{tabular}{|c|c|}
\hline ART ICLE INFO & A B S T RACT \\
\hline $\begin{array}{l}\text { Received: } 12 \text { January } 2019 \\
\text { Revised: } 29 \text { January } 2019 \\
\text { Accepted: } 2 \text { February } 2019 \\
\text { Available online: } 2 \text { March } 2019 \\
\text { DOI: } 10.29088 / \text { SAMI/AJCA.2019.2.184189 } \\
\text { K E Y W O R D S } \\
\text { Cobalt (III) Complexes } \\
\text { Structure } \\
\text { NMR Spectroscopy } \\
\text { Salen Ligands } \\
\text { Schiff-Base Ligand } \\
\text { Synthesis }\end{array}$ & $\begin{array}{l}\text { The synthesis of some new cobalt (III) complexes: [Co (5-Xsalen) } \\
\left(\mathrm{PEt}_{3}\right) \text { ] } \mathrm{ClO}_{4} \cdot \mathrm{H}_{2} \mathrm{O} \text { (where } \mathrm{X}=\mathrm{H}, \mathrm{NO}_{2}, \mathrm{Br}, \mathrm{OMe} \text { ) were synthesized and } \\
\text { characterized using elemental analysis, }{ }^{1} \mathrm{HNMR} \text {, IR and UV-Vis } \\
\text { spectroscopy. The summarized results of these spectral evidences } \\
\text { were in conformity with the structure of the synthesized complexes. } \\
\text { In this study, we synthesized four novel complexes of Co (III) by the } \\
\text { reaction of the metal ions with the salen ligands. The ligands } \\
\text { coordinated with the metal ions through } \mathrm{N} \text { - and O-donors. The } \\
\text { complexes exhibited a geometry based on the coordination number } \\
5 \text {. The results showed }{ }^{1} \mathrm{HNMR} \text { spectra of these complexes are } \\
\text { consistent with the suggest formulation and show that the cobalt in } \\
\text { these complexes is low spin. Its structure was established by } \\
{ }^{1} \mathrm{HNMR} \text {, IR and UV visible spectroscopy. }\end{array}$ \\
\hline
\end{tabular}

\section{GRA P H I C A L A B S T RACT}

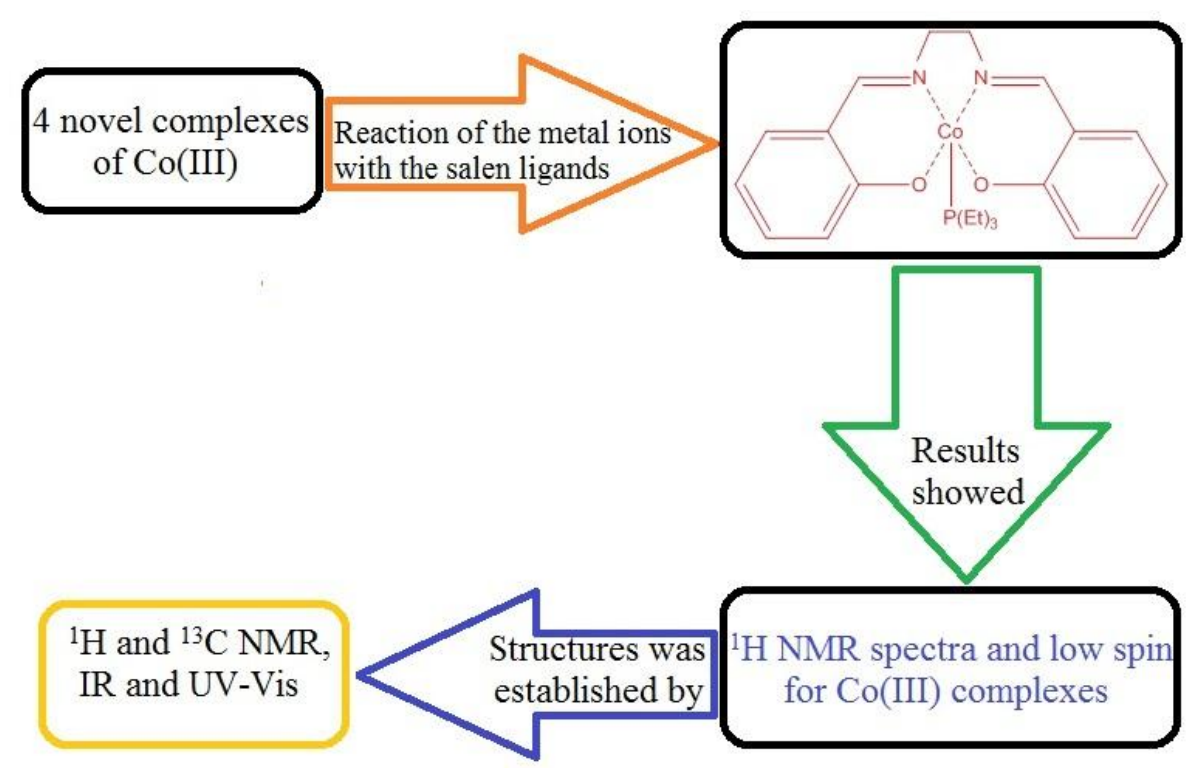

\footnotetext{
* Corresponding author's E-mail address: Alizadeh.r60@gmail.com

Sama Technical and Vocatinal Traning College, Islamic Azad university, Gachsaran Branch, Gachsaran, Iran.
} 


\section{Introduction}

Schiff base are capable of forming coordinate bonds with many of metal ions through both azomethine group and phenolic group or via its azomethine or phenolic groups [1]. A large number of Schiff bases and their complexes are significant interest and attention because of their biological activity including anti-tumor, antibacterial, fungicidal and anticarcinogenic properties [2]. Teridentate Schiff bases are well known to coordinate with various metal ions forming stable compounds, and some of these complexes are recognized as oxygen carriers [3]. Complexes of cobalt (II) involving derivatives of salicylaldehyde and aliphatic amines have received considerable attention because of their similarity to biological dioxygen carriers [3], as well as their potential as catalysts for the insertion of oxygen into organic substrates $[4,5]$. In particular, the dioxygen adducts of [Co (salen)] and their ring substituted analogues have received intensive investigation. To continue investigation in the field of Schiff base complexes, we reported here preparation and characterization of the new cobalt (III) complexes. In this study, a series of complexes of the type [Co (5-Xsalen) $\left.\left(\mathrm{PEt}_{3}\right)\right] \mathrm{ClO}_{4} \cdot \mathrm{H}_{2} \mathrm{O}\left(\mathrm{X}=\mathrm{H}, \mathrm{NO}_{2}, \mathrm{Br},-\mathrm{OMe}\right)$ has been synthesized and characterized by elemental analysis, UV-vis, IR, and ${ }^{1}$ HNMR spectroscopy.

\section{Experimental}

\section{Materials and Apparatus}

Ethylene diamine, 5-Methoxysalicylaldehyede, 5-nitro salicylaldehyede, salicylaldehyede, 5Bromosalicylaldehyede, cobalt(II) acetate, tetrahydrate, trietylphosphine, methanol, and sodium perchlorate, all of which were obtained from Merck, Fluka and Aldrich. All of the scanning UV-Vis spectra were recorded by Jasco V-530 pectrophotometer. The ${ }^{1} \mathrm{HNMR}$ spectra were recorded by Bruker Avance DPX 250 MHz spectrometer; IR spectra were recorded by Perkin Elmer Infrared spectrophotometer.

Elemental microanalysis (C.H.N), was performed using a Heraeus CHN-O-RAPID elemental analysis.

\section{Synthesis of the Ligands and Complexes}

The Schiff bases ligands were prepared from the condensation of 5Methoxysalicylaldehyede, nitrosalicylaldehyede, salicylaldehyede and 5-Bromo salicylaldehyede, with ethylene diamine in methanol as a solvent. The reaction molar ratio is (X-salicylaldehyede: ethylenediamine; 2:1). The separated precipitate was filtered, washed several times with minimum amount of methanol and dried under vacuum at room temperature. Cobalt (III) complexes under investigation were synthesized as follows; the ligand was dissolved in $(100 \mathrm{~mm})$ 
methanol and added to a metal salt (cobalt

(II) acetate) methanolic solution $(20 \mathrm{~mm})$.

The mixture was refluxed for $2 \mathrm{~h}$; the volume

of the mixture was reduced to one-third. On cooling a crude product was formed, which is collected by filtration and washed several times with methanol (according to the literature [6-8]).

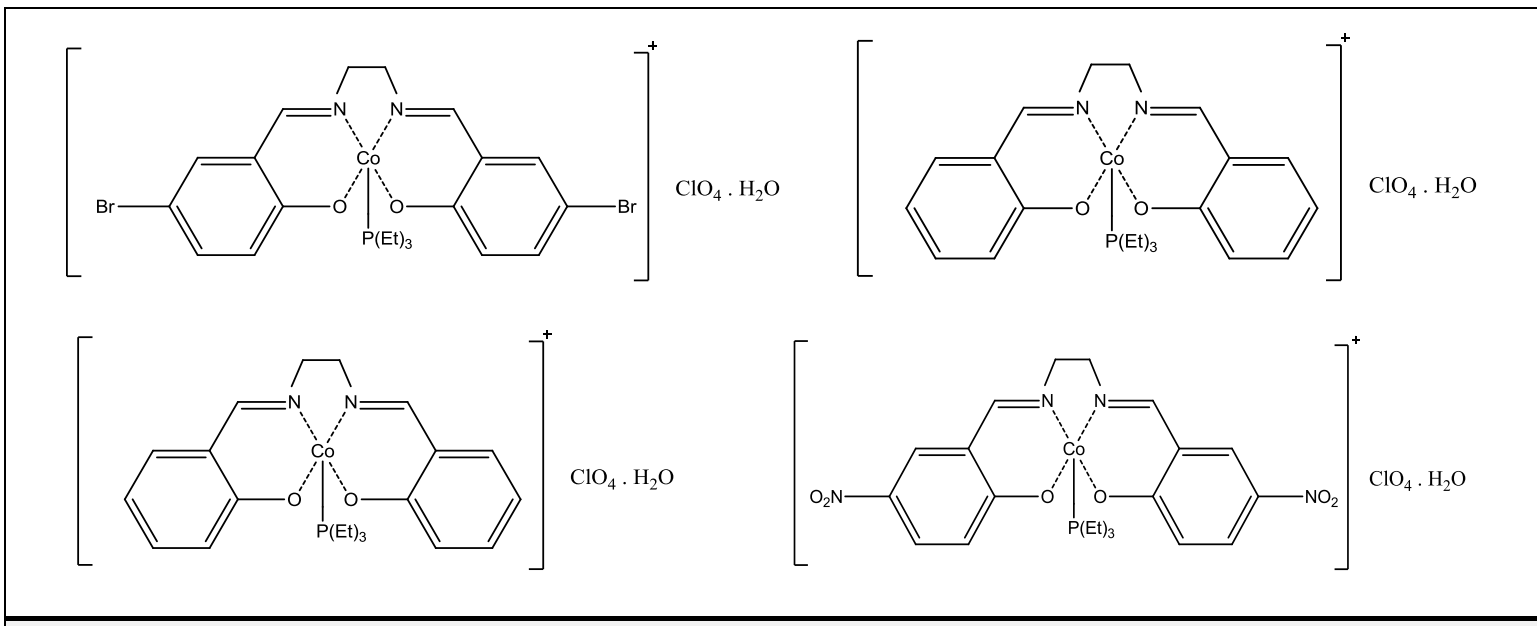

Scheme 1. Suggested structure of the complexes and ligands
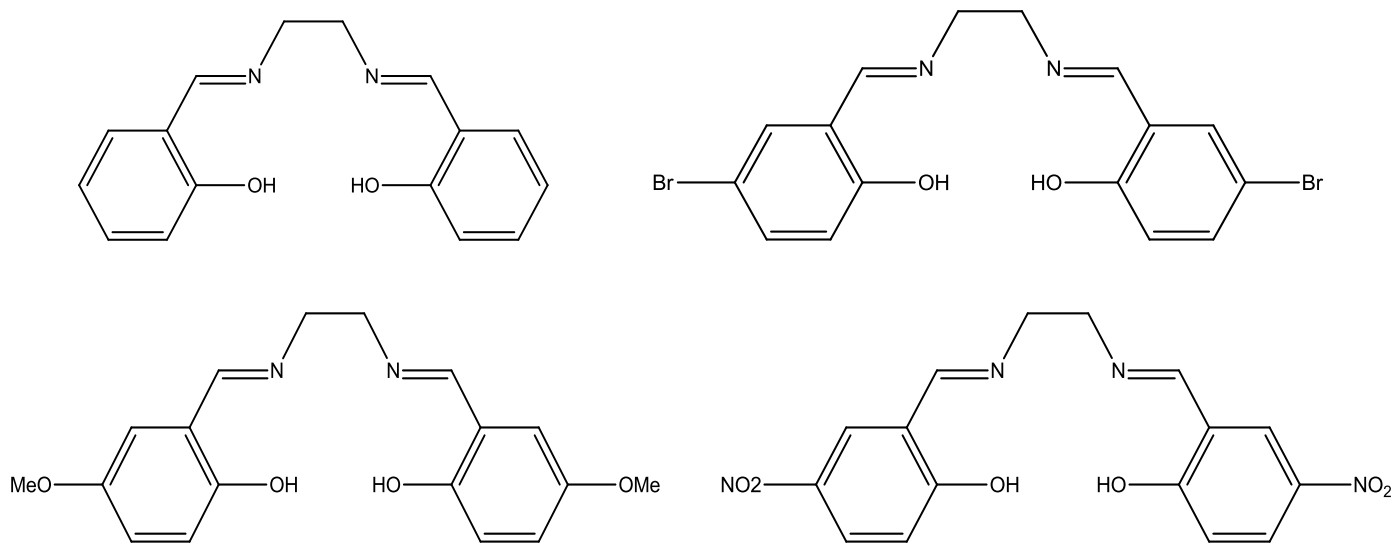

Scheme 2. Suggested structure of the complexes and ligands

Table 1. Elemental analyses [found (calcd.) (\%)] and wavelengths selected $(\lambda, \mathrm{nm})$ of the complexes

\begin{tabular}{ccccccc}
\hline Co(5- XSalen) & C & H & N & \multicolumn{3}{c}{ Wavelengths (nm) } \\
\hline Co(Salen) & $41.98(42.55)$ & $5.11(5.03)$ & $4.60(4.51)$ & 230 & 400 & 620 \\
Co(5-NO Salen $)^{2}$ & $45.37(37.17)$ & $4.4(4.11)$ & $4.02(3.92)$ & 210 & 370 & 570 \\
Co(5-Br Salen) & $36.07(36.75)$ & $4.02(4.07)$ & $3.95(3.89)$ & 220 & 240 & 613 \\
Co(5-OMe Salen) & $42.63(42.33)$ & $5.15(5.18)$ & $4.18(4.15)$ & 230 & 450 & 656 \\
\hline
\end{tabular}


Table 2. Infrared spectral data of the schiff base ligands and cobalt complexes $\left(\mathrm{cm}^{-1}\right)$

\begin{tabular}{ccccccc}
\hline Compound & $\mathbf{v ( C = N )}$ & $\mathbf{v ( C - o )}$ & $\mathbf{v}\left(\mathbf{C}-\mathbf{N O}_{2}\right)$ & $\mathbf{v ( C - B r})$ & $\mathbf{v ( M - N )}$ & $\mathbf{v ( M - 0 )}$ \\
\hline $\mathrm{H}_{2}$-Salen & 1653 & 1283 & - & - & - & - \\
$\mathrm{H}_{2}$ (5-NO2 Salen) & 1655 & 1216 & 1300 & - & - & - \\
$\mathrm{H}_{2}$ (5-Br Salen) & 1590 & 1270 & - & 690 & - & - \\
$\mathrm{H}_{2}$ (5-OMe Salen) & 1650 & 1280 & - & - & - & - \\
Co(Salen) & 1637 & 1300 & - & - & 550 & 510 \\
$\mathrm{Co}\left(5-\mathrm{NO}_{2}\right.$ Salen) & 1630 & 1110 & 1300 & - & 563 & 531 \\
$\mathrm{Co}(5-B r$ Salen) & 1625 & 1085 & - & 690 & 555 & 513 \\
$\mathrm{Co}(5-\mathrm{OMe}$ Salen) & 1605 & 1210 & - & - & 578 & 522 \\
\hline
\end{tabular}

\section{Results and discussion}

All the newly synthesized complexes were colored solids and soluble in DMSO, DMF and methanol. The analytical data were in good agreement with the proposed stoichiometry of the complexes. The electronic spectral and analytical data of cobalt complexes are presented in Tables 1.

\section{IR spectra}

In the complexes, the absorption band around $1600 \mathrm{~cm}^{-1}$ is assigned to an azomethine $(\mathrm{C}=\mathrm{N})$ group [9]. The phenolic (C-O) stretching band is observed at 1230$1290 \mathrm{~cm}^{-1}[9,10]$. The ring skeletal vibrations $(\mathrm{C}=\mathrm{C})$ were consistent in the region of 1440-1465 in all complexes [11]. Intense band in 1090-1100 is assigned to perchlorate stretching vibrations, which are typical of non-coordinating perchlorate [12]. The weak bands at $2845-2985 \mathrm{~cm}^{-1}$ in the ligands are related to $\mathrm{C}-\mathrm{H}$ modes of vibrations. In cobalt (III) complexes containing $\mathrm{PEt}_{3}$ these bands were very stronger, assignable to $\left(\mathrm{CH}_{3} ; \mathrm{CH}_{2}\right)$ vibrations of $\mathrm{PEt}_{3}$. The vibration band in 3000-3400 $\mathrm{cm}^{-1}$ is assigned to $\mathrm{O}-\mathrm{H}$ stretching due to $\mathrm{H}_{2} \mathrm{O}$ of the complexes [13]. The IR spectral frequencies of tetra dentate ligands and cobalt complexes are given in Table 2 .

\section{${ }^{1}$ HNMR spectra}

The ${ }^{1}$ HNMR spectra of these complexes are consistent with the suggest formulation and show that the cobalt in these complexes is low spin. In the ligands, the signals observed at 12.84 to $16.10 \mathrm{ppm}$ are attributed to the hydroxyl protons. The second signals observed around 12.00 to $12.52 \mathrm{ppm}$ are assigned to NH protons [14]. The absences of these protons in the complexes show that the Schiff bases are coordinated. The azomethine proton signals appeared at 8.22 to $8.63 \mathrm{ppm}$. By comparing the ${ }^{1} \mathrm{HNMR}$ spectra of all the Schiff bases with those of their corresponding Co(III) complexes, it is noted that there is a down field shift in the frequency of azomethine protons aliphatic bridge confirming coordination of the metal ionto these groups. The proton chemical shifts for the coordinated $\mathrm{PEt}_{3}$ appear at 0.70-1.76 ppm. ${ }^{1} \mathrm{HNMR}$ spectra of, 
substituted phenyl ring of Schiff bases show additional signals. A singlet signal at 3.42 ppm is assigned in the [Co (5 OMesalen) $\left.\left(\mathrm{PEt}_{3}\right)\right] \mathrm{ClO}_{4} \cdot \mathrm{H}_{2} \mathrm{O}$ that have OMe group. These results are in agreement with the observed previous results for metal complexes of phosphine as axial ligand [15-18].

\section{Conclusion}

In this study, we synthesized four novel complexes of Co (III) by the reaction of the metal ions with the salen ligands. The ligands coordinated with the metal ions through $\mathrm{N}$ - and O-donors. The complexes exhibited a geometry based on the coordination number 5. An attempt at prediction the structure and geometry of the complexes was made by elemental analysis, UV-vis, IR, and ${ }^{1}$ HNMR spectroscopy. All these characterizations put together lead us to propose the structures shown in Figs 1.

\section{Acknowledgements}

Financial support for this work from Gachsaran University is acknowledged.

\section{References}

[1]. V. Sheat, T.V. Waters, J. Inorg. Nucl. Chem., 1964, 26, 1221-1225.

[2]. N. Raman, A. Kulandaisamy, C. Thangaraja, K. Jeyasubramanian, Trans. Met. Chem., 2003, 28, 29-36.

[3]. C. Floriani, F. Calderazzo, J. Chem. Soc. (A), 1969, 946-953.
[4]. A. Nishinaga, H. Tojo, K. Nishizawa, T. Matsuura, J. Chem. Soc., Chem. Commun.,1974, 896-897.

[5]. A. Nishinaga, H. Tomita, K. Nishizawa, T. Matsuura, S. Ooi, K. Hirotsu, J. Chem. Soc., Dalton Trans., 1981, 1504-1514.

[6]. P.J. MacCarthy, R.J. Hovey, K. Ueno, A.E. Martel, J. Am. Chem. Soc., 1955, 77, 58205824.

[7]. N.S. Biradar, G.V. Karajagi, T.M. Aminabhavi, W.E. Rudzinski, Inorg. Chim. Acta, 1984, 82, 211-214.

[8]. M. Asadi, A.H. Sarvestani, Z. Asadi, M. Setoodeh Khah, Synth. React. Inorg. Met. Org. Chem., 2005, 35, 639-644.

[9]. M. Tumer, C. Celik, H. Koksal, S. Serin, Trans. Met. Chem., 1999, 24, 525-532.

[10]. A.D. Garnovskii, A.L. Nivorozhkin, V.I. Minkin, Coord. Chem. Rev. 1993, 126, 1-69.

[11]. S.K. Mondal, P. Poul, R. Ray. K. Nag, Trans. Met. Chem., 1984, 9, 247-250.

[12]. A.A. Khandar, S.A. Hosseini-Yazdi, Polyhedron, 2003, 22, 1481-1487.

[13]. S. Biswas, K. Mitra, C.H. Schwalbe, C.R. Lucas, S.K. Chattopadhyay, B. Adhikary, Inorg. Chim. Acta., 2005, 358, 2473-2481.

[14]. M. Asadi, Kh. Mohammadi, Sh. Esmaielzadeh, B. Etemadi, H.K. Fun, Polyhedron. 2009, 28, 1409-1418.

[15]. M. Asadi, A.H. Sarvestani, B. Hemateenejad, J. Chem. Res., 2002, 520-523. [16]. M. Asadi, A.H. Sarvestani, Z. Asadi, M. Setoodehkhah, Met. Org. Nano Met. Chem., 
2005, 35, 639-644.

[17]. M. Asadi, A.H. Sarvestani, M.B. Ahmadi,

Kh. Mohammadi, Z. Asadi, J. Chem.

Thermodynamics., 2004, 36, 141-146.
[18]. M. Asadi, A.H. Kianfar. S. Torabi, Kh. Mohammadi, J. Chem. Thermodynamics., 2008, 40, 523-528.

How to cite this manuscript: Rahman Alizadeh*, Nader Ghazinia, Synthesis, Experimental and Theoretical Characterization of Co (III) Complexes of 2Hydroxinaphthaldehyde, Advanced Journal of Chemistry-Section A (Adv. J. Chem. A) 2019, 2(3), 184-189. 